\title{
Evaluating the Evaluator: Towards Understanding Feed-back, Feed-up, and Feed-forward of Moroccan Doctorate Supervisors' Reports
}

\section{Bani Koumachi ${ }^{1 *}$}

\section{* Correspondence: \\ Bbani.koumachi@uit.ac.ma \\ 1. Department of English Studies, \\ School of Languages, Lettres and Arts, Ibn Tofail University, Kénitra, \\ Morocco}

Received: 15 August 2021

Revision: 12 November 2021

Accepted: 9 December 2021

Published online: 20 December 2021

\begin{abstract}
Supervisor's feedback is both a naysaying and a puzzling concern that has always tormented academics in higher education. Particularly, written feedback on pre-final or final versions of a submitted doctoral dissertation is indisputably the most significant step toward granting a doctoral student supervisee the right to defend his/her research project. It also constitutes a rich source on how students are to academically go about writing their dissertation and even go public as they are supposed to produce one or two articles before their vivas. The present research explores the written comments provided by supervisors on Moroccan doctorate supervisees' dissertations. It principally focuses on both overall and in-text comments and whether they serve as feed-back to take corrective actions for the errors made, feed-up to focus on strategies to attain the academic goal, or feedforward to be proactive and avoid disturbances that might affect the quality of the final work. A total of 40 supervisees from the English department at FLLA, Ibn Tofail University belonging to Language and Society Research Laboratory participated in the study. Data were collected using an online questionnaire through available Google forms platform. The results revealed that the total majority of supervisees tended to get a mixture of written remarks with a central focus on the quantity rather than on form. This is therefore a plus as to the agreement as well as the variance of the Moroccan supervisors in the use of these evaluation criteria while evaluating their supervisees' doctoral dissertations targeting different types of feedback with a huge focus of the cyclicity of their utilization.
\end{abstract}

Keywords: feed-back, feed-forward, feed-up, supervisor, supervisee, dissertation, higher education 


\section{Introduction}

Most supervisees have no idea what their examiners do with their theses and dissertations and most supervisors have no idea how others go about the process of evaluation except comments from here and there as well as anecdotes collected as supervisees in the past. Everyone has his/her suspicions about the evaluation process, especially in its feedback side. Supervisees have to wait for a long time to know how their supervisors view the evaluation operation, and there are even some who have to wait years as their respective supervisors keep changing strategies of dissertation evaluation operation (Chugh, Macht, \& Harreveld, 2021).

One of the foremost concerns for supervisors in Higher Education (henceforth HE) is to get the balance of quality of feedback and timeliness of feedback just right for students in order for them to derive the greatest benefit to their learning from that feedback. There are many challenges facing teachers when they consider the use of formative assessment and formative feedback and many variables to take into account in their practice, ranging from workload issues (for staff and students) to the value placed on the activities and feedback and how these relate to the student learning experience (Broadbent, Panadero, \& Boud, 2017).

HE supervisors are put in a position to evaluate potential doctorate holders by grading their academic work. This assessment is thought to hinge on assessing grammar, clarity, conciseness, and coherence-content and form. Having consistent assessment methods in the English studies department could have been a valuable advantage let alone cross departmentally in the same faculty. The consistency of these methods could also help students know what is expected of them, help them to be good writers, and put supervisors in a strong position where they would not be blamed for the work that does not conform to the rubrics of assessment. Regardless of the genre of the academic work presented, the supervisor has to adopt a certain balanced view towards evaluating that work and a well-adjusted manner of providing feedback (Fry, Ketteridge, \& Marshall, 2003).

Many are therefore the criteria that are to be considered by the supervisor so that he/she would help supervisees get to know their weaknesses and strengths. In the present study, four are selected to evaluate feedback on students' doctoral work: In-text feedback marks rubric which deals with marks for grammar, mechanics and style, In-text feedback comments rubric which concerns itself with comments to assess the content of the paper, end comments rubric which is about overall feedback in the form of small texts, and rubric development which deals with the technical organization of feedback in the form of rubrics of assessment (Dirkx, Joosten-ten Brinke, Arts, \& Van Diggelen, 2019).

The purpose of in-text feedback marks is to identify problematic areas insofar as grammar, mechanics, and style weaknesses that might weaken the work and leave students to criticism of being belittled first by the supervisors and second by the committee of examiners the day of the viva. For that reason, such types of in-text comments serve as feedback whose quantity is decisive in the quality of the work. If ever no such comments are provided, it might mean either of two things: either the work is perfect and error-free (an occurrence that is infrequent), or the work is not part of the assessment process (which is not again acceptable in that the work is academically supposed to be defended). Conversely, if it happens that the examiner marks every grammatical, mechanical, and stylistic error in the text, this also might mean the quality of the supervisee is low and this latter gets bogged down with the quantity of comments and this in any way helps in writing progress, or gets also psychologically incapacitated to the extent that the remaining work is overshadowed by the previous vicious comments. Examiners in this case adopt patterns as pedagogical stances where they provide approximately the exact feedback need (not provide any or provide much); otherwise burn-out or over-ambition could pop up (Hattie, 2009).

For the in-text feedback in the form of comments, the idea is to assess the content of the paper providing comments on the margins and how it could be developed. Worth noting here is that the comment on idea development is done by asking the examinee questions, rather than with plain statements and incite them to get engaged in dialog of critical thinking with the material being evaluated (Frankenberg-Garcia, 1999).

As to the end comments, they are forms of evaluative remarks and observations which are provided in the form of short sentences of feedback, contingent on the scope and nature of the assignment. The lengthier the work is, the more end comments the supervisee gets. It should be noted here also that the examiners need to overwhelm the supervisees with much intimidating feedback and not to offer less lest that students get overinvolved with the intricacies of finding the right way to answer the examiners rather than find the right solution to a genuine problem raised by the end comments. The end comments are much like an aggregate of comments raised during the process of evaluating the 
work, and the supervisor sees to it that the student gets the bigger picture of the whole work so that he/she would identify the possible best ways to put together all the pieces of the work and coherently craft it (OECD, 2001).

Furthermore, because the end comments have also the function of corroborating the grade the assignment is supposed to earn, the pedagogical philosophy of the examiner is decisive herein. Cogently, the tone, structure, and preciseness of the end comments are seen as forms of criticism on the content as well as the quality of the assignment writing. In this sense, the end comments and the way they are advanced shall either enable or disable the supervisee's ability towards becoming a better writer. This helps students become aware of writing as a process and a skill that needs various steps of refinement before the final version is yielded (Ramírez Balderas, \& Guillén Cuamatzi, 2018).

The final criterion against which the evaluation of an academic work is done is the rubric development. The idea is always making students understand and one of the efficient strategies to assess this understanding, which is supposed to lead to work improvement, is the establishment of rubrics in the form of criteria. A rubric is "the written-or guide - by which student performance or a product is judged" (Nelson, 2008, p. 38). Rubrics are significantly decisive in making students active learners and develop as novice writers. They can also make of them autonomous learners/writers who feel responsible for their own development. The objective of adopting clear rubrics is similarly crucial for giving incites for supervisees to "reach and lay out a vision of a well-done project or activity" (Nelson, 2008 , p. 36). The objective of the present research is to investigate the idea of whether evaluating higher education projects is based on personal experience and tendency or whether there are academic criteria that supervisors follow to judge the content and form of their supervisees' doctoral projects. Additionally, given that the evaluation process is linked to the provision of feedback, the provision of this later is of two types: feedback, feed-up and feed-forward and the reasons behind the use of each type.

The research questions this piece of research sets out to answer are:

1. Do supervisors differ in their way of evaluating (giving feedback) doctoral dissertations? (Are there any unified institutional criteria and instructions that offer little/any guidance about how a dissertation shall actually be assessed).

2. What types of criteria are considered by supervisors so that they would help supervisees get to know their weaknesses and strengths? (In-text feedback marks, In-text feedback comments, end comments, or rubric development)

3. What type of written comments (feed-back, feed-up or feed-forward) do supervisors provide on doctoral dissertations?

The primary focus of this study is to ascertain the quality and nature of feedback in HE by examining the doctoral dissertations of some of the supervisees and investigate whether the supervisors are disparate on the criteria they use in assessing the research at the tertiary level. The overall aim therefore is to encourage the teaching/supervising staff to focus more on the promotion of student research skills through formative assessment activities evaluation.

\section{Review of the Literature}

Supervisory relationships are awash with power negotiation and the Moroccan ones are not an exception. These relationships exhibit the master apprentice relationships which presuppose the teacher-the knowledgeable person and the student-the learning agent. In such a state of affairs, feedback or any form of evaluation, be it oral or written, becomes a form of teaching, with all what teaching could mean to people (Arend \& Davis, 2013). However, other relationships could exist, like when the supervisee is a practicing colleague, a friend, or a superior. But still, the focus of this study is on the student-supervisee-teacher-supervisor relationship not on how power is negotiated but on how evaluative comments are issued and in what type of behavior such supervisory environment is replete with.

In academia, the Moroccan supervisory environment, like any other environment, is no disparate insofar as in-text comments as forms of feedback are concerned. Written comments, seen therefore either as feedback or feed-forward, are classic comments provided on students' academic works that usually lead to attempts on the supervisee's part to perfect his/her scientific products. These academic comments necessarily communicate ideas about how academic writing is to be crafted and how an academic piece like a doctorate for instance is to be molded. It is through this kind of in-text comments that the supervisee becomes critical thinker and a conscious agent of the particularities and intricacies of academic writing and in terms of growth moves from a student-stage to a novice writer-stage, a journey of self-discovery. 


\subsection{Feedback: Definition and Types}

It may seem that feedback is a rather complex concept to write an article about. To escape the controversy of existing disparate views of learning and associated beliefs as well as the likelihood of effectives and efficiency in the use of feedback (Askew, 2000), a specific conceptual and operational definition is to be adopted that is related to how written feedback in higher education is provided and its quality and nature in HE by examining a sample of doctoral dissertations and whether the supervisors are dissimilar on the criteria they use in assessing the research projects.

In a broad sense, the term 'feedback' refers to the "information provided by an agent (e.g., teacher, peer, books, parents, self, experience) regarding aspects of one's performance or understanding, thus being a consequence of performance or understanding" (Hattie \& Timperley, 2007 as reported in Lane, 2015, p. 90). The idea here is that feedback as evaluative observations could be either written or oral information that emanates from an accountable teaching source and which concerns some performance with the objective of improving it. More explicitly, feedback is also the "information with which a learner can confirm, add to, overwrite, tune, or restructure information in memory, whether that information is domain knowledge, metacognitive knowledge, belief about self and tasks, or cognitive tactics and strategies" (Winner \& Butler, 1994 as cited in Spector, Merrill, Elen, \& Bishop, 2014). Feedback in this sense contains not only the first layer of meaning which concerns feedback as corrective procedures, but also the second layer of meaning where feedback is seen as feed-forward with the objective of taking cognitively future measures to make the work perfect as a process. The effectiveness therefore of feedback/feed-forward is to help the learner/writer get focused with the objective, desired performance, and enable him/her to perform well and understand the advancement process, learning to write and research in our case (Ramaprasad, 1983 as cited in Bajaj, Kaur, Arora, \& Singh, 2018).

On that account and for more precision on the meaning dimensions then of feedback, it is of three types. According to Lipnevich and Smith (2018), feed-back concerns itself with the 'how' of the process. The aim is to get informed about the task performance goals, and expectancy of success or failure. For Railean (2019), feed-back in higher education has one sole objective whatever its nature is to develop professional competencies. Giving feed-back therefore aims at motivating students to have a critical attitude towards the learning as well as the skills targeted processes. Feed-back in this situation is in equal measure either evaluative gauging what is taught and learnt, prescriptive providing guidance and advice on the process in a scaffolding manner on the part of the feed-back giver/supervisor, and descriptive displaying characteristics of authenticity and pertinence.

Always with feed-back being influentially related to the 'how' stage, Rowan and Bigum (2012) state that it has changed in nature and means of issuance. Feed-back has become electronic and transmitted through digital learning platforms which expand the possibility of receiving it timely and saving time for both parties: supervisee and supervisor. Succinctly, teacher written feed-back should be aligned with instruction helping students/supervisees to know what they are supposed to produce if ever they want to join the academic community of researchers (Lee, 2019). The 'how' stage is definitely connected to "the learning goals and success criteria set up in the" (Lee, 2019, p. 78) 'where' stage- feed-up, and related to 'where to next'-feed-forward stage as well as "it should lead to effective learning in the "feed-forward" (Lee, 2019, p. 78) in this stage.

The feed-up or the 'where' stage focuses on the statement of objective attainment (Lipnevich \& Smith, 2018). The accomplishment of performance-oriented goals of this stage is to be prospectively considered. Therefore, the feed-up stage of feedback is conscience-raising for the supervisee to have prospectively the potential to see to it that he/she can perform well if he/she gets the skill to incorporate and understand what is demanded from him/her as a would-be academic (Rowan \& Bigum, 2012).

The "where to next" or feed-forward of feedback is the third element. In this stage, the aim is to supply the supervisee with the necessary strategies to ease him/her into the process of learning, understanding and producing a quality work, in terms of scientifically rigorous research. Feeding forward is highly efficient in case the information/observation/comment and "leads to greater possibilities in learning" (Hattie \& Timperley, 2007, p. 80). These learning possibilities are couched in the strategies that inspire practically possible solutions and clear guidance on how "to address problems and/or to impact on the evolution of students learning" (Benjamin, 2012 as cited in Railean, 2019, p. 244). The concept of feed-forward additionally underscores how formative assessment is essential in the learning enterprise. The idea is to facilitate the move from feed-back to feed-up and ultimately to feed-forward (Rowan \& Bigum, 2012). 
The interconnectedness of these three stages is decisive in being efficient, in attaining the desired goals, and effective in achieving them with the scholastic and systematic ways of understanding, autonomy, and participation. Specifically, feed-up is descriptively characterizing the goal; feed-back is mere reaction to supervisees' work; and feed-forward is being able to impact students'/supervisees' strategies and schemes to become good learners and academics. Altogether, the supervisees have to bear in mind answering the three questions if ever they want their supervisees to produce quality research work. The focus shall therefore be on designing goals, a feed-up component, emphasizing the mechanisms of the academic process, feed-back factor, and concentrating on enabling prospective academic actions immersed in the didactic action (Railean, 2019). In a nutshell, when supervisors feed-back their supervisees on their work goals, and when they assess them formatively, they connect feed-back to feed-up; and when their feedback is geared towards mastering the guidance and strategies to produce quality work, feed-back serves the purpose of feed-forward (Lee, 2019).

\subsection{Feedback as Part of Formative Assessment}

Evaluative comments as forms of feedback are a major component of the formative assessment process. Formative assessment helps teachers provide pertinent information about students' work and even monitor their learning as it is supposed to be embedded in learning, teach what is assessed, and assess what is taught, to quote (Fielder, 2003). Crafting good evaluative comments as well as the timeliness of providing them is a skill that is supposed to be mastered by supervisors so that students would be guided in their use of in-text evaluative remarks that would enable them not disable them academically speaking (Brookhart, 2008). Providing these informative comments is part of formative assessment process whose rules both supervisor and supervisee have to know and be versed in.

The power of good evaluative comments given by supervisors as forms of formative feedback lies in being good cognitive and motivational vectors driving towards producing good scientific products. Cognitively, the students become critical thinkers as they understand what is academically needed of them to become good writers and researchers. Motivationally, the moment the supervisees feel that they started to master the craft of writing and research, they get a boost of motivation to finish their project and even embark on others in parallel.

To be effective in supporting feedback, feedback needs not only to tell them if they are right or wrong as this is summative in a sense, but to push students forward where they are descriptively driven in a scaffolding manner in a way to discover the process and manipulate it (Frey \& Fisher, 2011). Feedback in the form of formative assessment has success as well as understanding criteria outlined targeting progress and answering forcefully the three questions advance earlier: the 'how'-feed-back, the 'where'-feed-up, and the 'where to next'-feed-forward (Heritage, 2010). What attests to its formative nature, is that it is not only given by teachers/supervisors but also many as mentioned earlier, peers, machines, books, parents, or even the self. Metacognitively, supervisees get into a dialog with the self by thinking about their thinking and end up being effective in producing competent performance-quality research as a case in point.

On the same line of reasoning, Sadler (1989) stressed that a similar conception of work quality as that of the supervisor is what supervisees have to entertain if they want to monitor his/her work and engage metacognitively in the research process. Thus, three factors are involved: possess a concept of standard. This means that the student is at the 'how' stage of feed-back as he/she needs a benchmark against which he/she has to spring if ever they want to produce any quality work. The second is to compare the current level of performance with the benchmark set earlier. That is to say that students have to possess the compelling and enabling strategies to attain the goals set before, moving from feedback to feed-up. The last factor emphasizes the engagement in the appropriate actions which lead influentially and practically to the achievement of the goals, producing the desired work by being feed-forward actions (cited in McMillan, 2013).

Irons (2009) is specific in approaching assessment and feedback. Formative assessment for her is "Any task or activity which creates feedback (or feedforward [feed-up]) for students about their learning. Formative assessment does not carry a grade which is subsequently used in a summative judgement" (p.7). Formative feedback is naturally connected to it in that it constitutes "any information, process or activity which affords or accelerates student learning based on comments relating to either formative assessment or summative assessment activities" (p.7). Irons therefore sees that there is a close connection between formative assessment and formative feedback despite the fact feedback can occur on summative assessment. The proof comes from both Wiliam and Black (1996) who believe that feedback is a significant component of formative assessment because the moment the supervisors diagnose supervisees' 
inadequacies in content or form, the latter have to constructively and meta-cognitively act upon the product to make of it a quality product (as cited in Irons, 2009).

\subsection{What Research Says about Evaluative Comments}

The first studies and theories about feedback begun by Thorndike's Law of Effect and Skinner's behaviorist approach to learning, then the cognitive-based research in the late 1960s and early 1970s, and lastly the new-millennial shift towards feedback for learning (Burke \& Pieterick, 2010). From the psychological perspective of the behaviorist approach to learning, there were two types of reactions towards the behavior of the student; the first reaction was seen as positive feedback and was perceived as "positive reinforcement" to affect learning, and the other reaction was understood as negative feedback which was a "punished behavior" with a view to be conditioned and altered later (McNamara, 1999). Feedback in the form of punishment or reinforcement is actually geared towards effectiveness in the targeted/drilled behavior (Bangert-Drowns, Kulik, Kulik, \& Morgan, 1991).

The cognitive-based research of the late 1960s and early 1970s no longer approaches learning 'behavioristically' as this error and trail mechanism is no more a valid reality. The idea, therefore, is that the student is an essential agent in the learning-teaching enterprise. In the feedback process, as well as its type and the context where it is given, the student is decisive as he/she can affect and be affected by the internal along with the external one. The cognitive operations including but not restricted to perception, frame of reference, attitudes and motivation, play the role of sifting knowledge sent in the form of evaluative comments, making therefore of the learners/students a fundamental agent in the meaning-making process of feedback actions and content (Çeliköz, Erişen, \& Şahin, 2016).

In late 1970s and beginning 1980s, suspicion loomed over the validity of stimulus-response view and the discovery/the paradigmatic shift towards viewing feedback from this perspective had no effect whatsoever on feedback (Kulhavy \& Wager, 1993 as cited in Mayer \& Alexander, 2017). The paradigm shift which focused on the idea that feedback is organically connected to learners' cognitive and metacognitive processes, views feedback as an information processing operation where encoding of feedback information is done by the teacher and the decoding is done by the learner to act upon. The informational characteristic of feedback in such an epoch (Mayer \& Alexander, 2017; Mory, 1992) paved the way for another related conceptualization of feedback, the constructivist perspective. This philosophy stipulates that "learning is the construction and reconstruction of knowledge by each individual from their own ideas and previous experience" (Robins, 2012, p.35). In other words, learners create new knowledge out of existing knowledge and meaning is generated within the experience context of that newly created knowledge filtered through the cognitive structure of the creator-learner (Laurillard, 2013). The shift to this understanding (the constructively aligned feedback) of learning and teaching shifted also the view towards feedback. The written feedback, therefore, moves from "talking about feedback on learning to feedback for learning" (Burke \& Pieterick, 2010, p.12).

\section{Methodology}

\section{1 Research Design}

The major objective of feedback giving is to make the student aware of the status quo of the research ability, inform about the strategies, and offer pieces of advice about how to attain prescribed goals-producing quality research work (Hattie \& Timperley, 2007 as mentioned in Irons, 2009, p.21). A plethora of research has been produced to get to terms with how feedback can be enhanced to boost supervisees-novice writers and dig into their full potential to grow academically (Holland, 2008). Regardless of the fact that there has always been a problem in answering questions about feedback efficacy because of design inconsistencies Guénette (2007 cited in Irons, 2009), this study adopts an exploratory research design.

This methodological decision is justified by the paucity of studies on feedback in the Moroccan context and therefore it is conducted as a research problem when there are few or no earlier studies to refer to. McNabb (2004) states in this sense that exploratory research is done mainly for two aims: (1) as a preparatory phase for a study to gain insights, or (2) as an information-gathering stage to solve an immediate problem. That having been said and in either case, the present study adopts this design to serve as an in-depth attempt to discover the related factors and manifestations of feedback in higher education.

Even though this type of design is rarely used as a stand-alone design and works as a small sample-design, yet it informs deeply about the research gap chosen and the objectives targeted. Additionally, data collection in such type 
of research may involve quantitative as well as qualitative methods or a combination of the two. Both data gathered could be either primary or secondary but still their validity is guaranteed in exploratory research (Mcnabb, 2015).

\subsection{Sample and Sampling Procedure}

The present research aims at exploring the written feedback provided by supervisors on Moroccan doctorate supervisees' tertiary research work. It essentially focuses on any in-text or overall comments provided by supervisors and whether they serve as feed-back, feed-up, or feed-forward vis-a-vis the quality of the final work. A total of 70 university EFL supervisees from the English department at Ibn Tofail University belonging to Language and Society Research Laboratory participated in the study were used as a sample for the present study and responded to an online survey.

The doctoral students enrolled in one of the school's research laboratories constitute therefore the target population for the present study. A sample of this population shall be drawn non-probabilistically. The hindrance of having a probabilistic sample out of this population that is representative and increases the possibility of overgeneralizing results to other similar settings lies in the absence of a fundamental criterion against which a random sample could be adopted and favors the choice of a non-random one, the sampling census. Subsequently, opting for non-probability sampling is geared towards the researcher selecting a sample based on his/her subjective judgment rather than on random selection.

The sample type adopted is selected through convenient or opportunity and purposive sampling strategies given many reasons inherent in these strategies. The convenient mode has to do with the availability in determining the participants of the research being conducted. Therefore, the researcher, in an unstructured way, contacted his and other professors' supervisees in different ways with the help of colleagues, invited them and sought their consent to participate. Furthermore, the purposive mode is based on the researcher's knowledge about the population of the study. The researcher has prior knowledge of his study purpose and he knows that these participants are in a good position to provide him with data about the variable under study, evaluative comments of their supervisors on their doctorate dissertations. Specifically, the type of purposive sampling used here is the Maximum Variation Sampling (Seidman, 2019). This subtype helps collect a wide array of participants with dissimilar viewpoints to study a certain phenomenon-the variable under scrutiny herein.

\subsection{Instrument}

Experimental research is appropriate when the researcher targets the ascertaining of causal relationships between the dependent(s) and independent(s) variables, the latter is possibly and ethically manipulated, and some randomness is respected either at the level of sampling or assigning subjects to different conditions. It stands to reason, therefore, that the approach which is preferred herein in the present study is non-experimental as these conditions are not met. The adoption of this approach is done against these reasons: The research questions tackle a single variable, evaluative comments (feed-back, feed-up, and feed-forward) rather than statistical relationships where two or more variables are included. Additionally, the research questions deal with non-causal statistical relationship between variables.

Moreover, a survey questionnaire is used for the purpose of collecting data about the kind and utility of evaluative observations by supervisors, be it feed-back, feed-up, or feed-forward. This online feedback questionnaire was deemed appropriate during the COVID-19 confinement period, that's why supervisees and researchers had no other choice in terms of answering mode. Eventually, two types of questions and items were chosen: a multiple-choice and rankorder, or Likert-scale. In this sense, the instrument is a structured type of questionnaire that consists of 40 items/questions with totally pre-determined response options. Respondents have no other options except the closed questions/items on specific phenomena around which the questions/items are woven. In the social sciences, a structured questionnaire has the advantage of highly saving time by containing simple questions and items, clear and unambiguous instructions to guarantee smoothness from one part to another. The second benefit is that the questions/items are standardized with common and self-explanatory meaning. So, in a survey like this, the aim is that the respondent should find no difficulty in comprehending the meaning of questions/items that the researcher set forth. The third help such types of questionnaires offers is their being ideal for statistics. That is, they are excellent means whereby quantitative data are gathered and hence variables relationships are studied and bias is reduced (Bechhofer \& Paterson, 2012). Eventually, confidentiality and anonymity of the survey adopted helped in the high rate of the returned rate. 


\subsection{Data Collection Procedure}

The data collection process started in the beginning of the academic year 2020/2021, specifically during the COVID19 confinement period. In the first step, the researcher, conforming to the ethics of doing research, having permissions, and guaranteeing that the data will be used for academic purposes, had the dean's, department chair's, and the school research laboratory director's consent to contact supervisees of the faculty in any way convenient to him.

In the second step, and after the researcher went through these academic as well as legal procedures, he received the consent of the majority of participants and started sending surveys to all of them. Thirty-eight supervisees filled completely the survey with no objection or inquiry about any ambiguity of the questionnaire content proving that the survey was quite clear and unambiguous. That is, the participants expressed no concern about the content clarity, questions/items form, and time to complete the survey. The return rate was about $99 \%$.

\subsection{Data Analysis}

For a well-founded analysis of the data gathered appropriate statistical tools are used. Therefore, to answer the research questions posed for the present study, data description and discussion are supported by the Statistical Package for the IBM Social Sciences Program (SPSS), version 22.0. Two types of statistics are going to be used in this study: descriptive and inferential. The descriptive statistics shall be dealing with frequencies, standard deviations, and means that will be calculated for all dimensions and statements. As to the inferential statistics, a spearman rank-order correlation coefficients test shall be used to determine whether experimentally observed results are consistent with the null hypothesis. It is noteworthy here that such a non-parametric test is used even if parametric conditions of validity are not met (Gibbons \& Chakraborti, 2021).

Preliminary statistical analyses are to be conducted among the main variables of the study to ascertain the assumed relationships. Reliability and internal consistency of the data, that are supposed to be obtained from the main data collection instrument, the questionnaire, are guaranteed using the most commonly used measure of internal consistency reliability test, Cronbach alpha $(\alpha)$. Noteworthy here is that there are other estimates of reliability: testretest reliability, alternate-form reliability, and internal consistency reliability which cannot be used in the present study for various reasons. For the test-retest reliability, it seems that administering the questionnaire for the participants twice would result in knowledge growth of the content and boredom on the part of the participants who will find themselves answering the same instrument twice.

A more obvious reason would be guaranteeing the willingness to respond twice for the same data collection tool, which would probably push some to drop and hence affect reliability. As to the second type, alternate-form reliability, it refers to the amount of agreement between two or more research instruments such as two different questionnaires on a research construct that are administered at nearly the same point in time (Miller, 2015 as cited in Bolarinwa, 2015). The feasibility of such a reliability is hindered by the fact that we have one instrument that is administered and not more. Finally, the internal consistency reliability concerns the extent to which items on the test or instrument are measuring the same thing. The deterrent factor here is the different indices that are used in such a reliability test, an operation that is not feasible in our case; however, Cronbach alpha $(\alpha)$ test is deemed feasible and appropriate.

Table 1. Reliability statistics of the scale

\begin{tabular}{c|c}
\hline Cronbach's Alpha & N of Items \\
\hline .879 & 40 \\
\hline
\end{tabular}

Thus, the first step of the analysis is Cronbach alpha $(\alpha)$ test. The objective is to determine how consistent are the items in measuring the variables they were designed to measure. The alpha coefficient obtained for the whole questionnaire used in this study using the entire sample of 38 participants was .90 (rounded up from .87 after results of the corrected item-total correlations) (Table 1 above), suggesting therefore that the items had relatively high internal consistency for the scale used with this specific sample. We could safely conclude that the measurement design is highly credible. A reliability coefficient of .70 or higher was considered acceptable in most social science research situations (Fazlagić, 2017; Nunnally, 1978). 


\section{Findings}

This study was conducted from February through April 2021 and the data were collected via an online survey questionnaire. Almost all doctoral students of the faculty of Languages, Lettres, and Arts (FLLA), Ibn Tofail University were invited by email to participate in the study as they were thought to have had received particularly some feedback for specific written documents of their doctorate theses from their supervisors.

The feedback online survey is composed of two sections with seven parts. The first section contains four parts which revolve around rubrics of feedback assessment used by the teachers and perceived by doctoral students, while the fifth deals with existence and non-existence of feedback and constitutes the second section. Therefore, the first part of the first section takes care of the first criterion of feedback assessment, the In-text feedback marks rubric which deals with marks for grammar, mechanics, and style through seven questions. The first and second questions of this part were about grammar errors marking. The participants of the present study acknowledge that their professors mark grammar errors and they sometime mark specific patterns of grammatical errors ( $\mathrm{N}=59,84.3 \%$ and $\mathrm{N}=28$, 40\% respectively). They also showed in the third, fourth, and fifth questions that their professors mark for stylistics errors $(\mathrm{N}=54,77.1 \%)$ with particular focus on sentence variety $(\mathrm{N}=27,38.6 \%)$ as opposed to conciseness and achieving emphasis because too many sentences with the same structure and length can grow monotonous for readers. Also varying sentence style and structure can also reduce repetition and add emphasis. The frequency of marking such errors was sometimes done $(\mathrm{N}=32,45.7 \%)$ as well. For the sixth and seventh questions which were about marking mechanics errors, $(\mathrm{N}=58$, $82.9 \%)$ of the participants stated that their supervisors mark this type of errors with a rare frequency of $(\mathrm{N}=26,37.1 \%)$.

The second part of the same section deals with the In-text feedback comments rubric which concerns itself with comments to assess the content of the paper. In the first question, $(\mathrm{N}=32,45.7 \%)$ of the participants mentioned that their supervisors often use questions instead of statements, with an emphasis on what, why, and how question formats $(\mathrm{N}=35,50 \%)$. Similarly, $(\mathrm{N}=42,60 \%)$ of the questions asked by the same supervisors are pertinent, and almost every one of the students provided a different explanation for the choice of in-text feedback comments with a small difference $(\mathrm{N}=4,5.7 \%)$ who ascribed their use to try on the part of the supervisors to understand what the supervisee meant by a given statement.

In the third part of the first section, the focus was on end comments rubric which is about overall feedback in the form of small texts. The first question was about the frequency of using end comments instead of in-text feedback comments and margin comments. ( $\mathrm{N}=27,38.6 \%)$ of the respondents commented that the overall comments are sometimes made and also $(\mathrm{N}=27,38.6 \%)$ of them often receive end comments based on remarks and corrections within a research text used by the supervisors to say that a piece of research is representative of a quality found throughout the paper.

Moreover, the fourth part of section one focuses on another criterion of feedback assessment, rubric development. This criterion deals with the technical organization of feedback in the form of rubrics of assessment and includes ten questions. The first question which is about whether or not the supervisors use various assessment rubrics revealed that $(\mathrm{N}=31,44.3 \%)$ of the examinees declared that their supervisors sometimes use these rubrics. From question two through question ten, the respondents preferred to say that it is often that their supervisors care about the use of a title, an engaging introduction, and a thesis statement in their research texts; about following all directions of assignment so that their essay fulfills all the requirements and answers all parts of the research problem; about the consistency in the use of MLA/APA formatting style and in-text citations; about the paragraphing and development of logical rhetorical organization; about the use of supporting textual example to fulfill coherence and cohesion of the text produced; about the use of length requirements as to chapter balance; about the use of word choice and sentence crafting when varying vocabulary items and using specific language; about the careful use of grammatical sentences and mechanics; about the research text being proofread and spelling-mistakes free $(\mathrm{N}=33,47.1 \% ; \mathrm{N}=32,45.7 \% ; \mathrm{N}=28$, $40 \% ; \mathrm{N}=29,41.4 \% ; \mathrm{N}=25,35.7 \% ; \mathrm{N}=29,41.4 \% ; \mathrm{N}=27,38.6 \% ; \mathrm{N}=29,41.4 \% ; \mathrm{N}=30,42.9$ respectively).

The second section of the survey questionnaire deals with the type of written comments supervisors use when evaluating their supervisees' dissertations. The objective is to see whether these types of feed-back, feed-back, feedup, and feed-forward, exist or not. The first feed-back question is about the frequency in which the professors provide supervisees with information about their progress. It seems that the answer to this question $(\mathrm{N}=22,31$. 4\%), reveals that they often receive written comments on how they are at different stages of their research writing. The second question showed that $(\mathrm{N}=25,35.7 \%)$ of the respondents sometimes receive feed-back on how to get to the next stage. The last question which complements the previous one revealed that $(\mathrm{N}=30,42.9 \%)$ of the supervisees often get feedback on good parts and highlight things to be sharpened later in the process. 
The second part deals with feed-up and its first question demonstrated that $(\mathrm{N}=32,45.7 \%)$ of supervisees see that supervisors often establish purpose while assessing for the quality of the research text. For the second question, ( $\mathrm{N}=29$, $41.4 \%$ ) of the sample stated that supervisors also often offer evaluative observations that serve as information to guide them through the research process. The third question of this part evaluates how often the supervisees feel that what they are given as a feed-up form eventually serves as a true assessment of their research work. It seems that in conformity with what has already been found, $(\mathrm{N}=39,42.9 \%)$ of the supervisees often feel the written observations issued are truly evaluative of their work.

The last part of section two is the evaluative comments related to the feed-forward form of feedback. The first question showed that $(\mathrm{N}=49,70 \%)$ of the supervisees stated that they sometimes get as evaluative observation which serve as data to plan future feedback, and that $(\mathrm{N}=31,44.3 \%)$ of them consider the same evaluative observations as strategies that guide them through the research process. The last question of this series revolves around the possibility of what the supervisors feed forward constitutes clear solutions and indications on how to address future problems concerning their research skill evolution. It was found that $(\mathrm{N}=39,42.9 \%)$ of the supervisees think that they get inspired by the written evaluative comments offered by supervisors as they boost their research skill for future initiatives.

Table 2. Correlation of the feedback construct types and the feedback criteria

\begin{tabular}{|c|c|c|c|c|}
\hline & & & $\begin{array}{c}\text { Feedback Construct } \\
\text { Types }\end{array}$ & $\begin{array}{l}\text { Feedback } \\
\text { Criteria }\end{array}$ \\
\hline \multirow{6}{*}{ Spearman's rho } & \multirow{3}{*}{$\begin{array}{l}\text { Feedback Construct } \\
\text { Types }\end{array}$} & Correlation Coefficient & 1,000 & ,812 \\
\hline & & Sig. (2-tailed) & . & ,000 \\
\hline & & $\mathrm{N}$ & 70 & 70 \\
\hline & \multirow[t]{3}{*}{ Feedback Criteria } & Correlation Coefficient & ,812 & 1,000 \\
\hline & & Sig. (2-tailed) &, 000 & . \\
\hline & & $\mathrm{N}$ & 70 & 70 \\
\hline
\end{tabular}

The running of the Spearman rank-order correlation was justified on the basis of having ordinal data and for the purpose of determining the association between the two constructs under study: the feedback construct types and the feedback criteria. The correlation matrix generated (Table 2 above) revealed that the correlation between the main variables of the study with the 70 respondents involved is statistically significant at $(r h o=.812, N=70, p=.000)$. The relationship is positive and strong between the existence of the feedback criteria, In-text feedback marks rubric, Intext feedback comments rubric, end comments rubric, and rubric development and the feedback construct types, feedback, feed-up, and feed-forward. We are allowed therefore to conclude safely that from our two-tailed prediction of the studied relationship that the null hypothesis that there is no association between the two co-variables is rejected in favor of the alternative one. Consequently, the existence of this construct in the supervisees papers is proof enough that the supervisors do their job and that whatever is provided as feedback takes the forms already investigated; this construct ranges from feedback dealing with general research guide to the provision of palpable strategies that could help supervisees attain the predetermined research goals, to insinuation to future ability to integrate the research academia.

\section{Discussion and Conclusion}

The findings of the first part of the survey, In-text feedback marks rubric, show that the supervisors in our case mark the grammar, mechanics, and style weaknesses as well as their patterns. This is evocative of the supervisors doing their jobs as they try to boost the quality of their supervisees' academic work because they probably feel that it is a matter of face and academic reputation. This goes hand in hand with what Hyland (2019) preaches as he focused on the idea that writing drafts, including those designed for publication, use different rubrics as "they are useful in making grading decisions explicit and showing what the teacher values in a particular piece of writing" (p.181). 
Another remark is the frequency whereby these evaluative in-text feedback remarks are done. There seems to be a great deal of focus on the grammatical, mechanical, as well as the stylistic side of the work quality as this shows how both supervisee and supervisor suffer during the supervision period to produce a quality neat work. In this regard, Dobinson and Dunworth (2018) back up the idea of using what they call the micro level feedback which supervisors or work evaluators often use as standardized rubrics mandated by the research units at higher levels. Also as reported in Hyland and Hyland (2019), Bitchener et al. (2010) surveyed thirty-five supervisors across three disciplines and found that the feedback provided was critical in scaffolding student learning in driving them along the route to being autonomous learners. Additionally, the same sample of supervisors vowed that their feedback was on content as well as comments focused on linguistic accuracy.

Moreover, the findings of the second part reveal clearly that the supervisors tend to use various types of questions, why, what, how which are often pertinent ones as in-text feedback comments with the objective to make the supervisees' lives easier and help them reflect critically on the quality of their papers. This is in line with what Andre and Heartfield (2011) found. The two scholars stated that feedback assessment rubrics and other feedback frameworks help in providing in-text feedback comments which on their turn bring focus to learning. In-text feedback comments in a learning portfolio are learning-focused and provide justification for the learning process, direction for resources, and relevant encouraging models for good students. Another backup comes from Breed and Spittle (2020) who insisted on the idea that turning feedback, in-text feedback comments into questions helps to guide and evaluate learning.

In the third part of the first section, the focus was on end comments rubric which is about overall feedback in the form of small texts. The first question was about the frequency of using end comments instead of in-text feedback comments and margin comments. In the second question, $(\mathrm{N}=27,38.6 \%)$ of the respondents commented that the overall comments are sometimes made and also $(\mathrm{N}=27,38.6 \%)$ of them often receive end comments based on remarks and correction within a research text used by the supervisors to say that a piece of a research is representative of a quality found throughout the paper. For the third question, $(\mathrm{N}=29,41.4 \%)$ said the end comments do not differ that much from remarks and corrections within the text, and this is suggestive of either how the two types of feedback are perceived of by the doctoral students or how elusive they are when made by the supervisors. The question before the last one of this part concerns whether the end comments provided by the supervisors articulate the bigger picture of what is needed from supervisees as novice researchers. The answer $(\mathrm{N}=29,41.4 \%)$ of these respondents see that it is very much evocative of it is that supervisees are to get academically from their supervisees. The last question communicates that $(\mathrm{N}=32,45.7 \%)$ of the respondents very much agree with the statement that the end comments provided are enough to help identify their strengths and weaknesses as supervisees.

The findings of the final feedback assessment criterion, rubric development, show that the respondents agree on the fact that their supervisors use this rubric to investigate the idea that evaluating higher education projects is not based on personal experience and tendency but specifically on academic criteria that they follow to judge the content and form of their supervisees' work. This systematic way of work evaluation is consistent with the objective to make the supervisees as novice writers and researchers autonomous and critical thinkers; such qualities are needed in academia for any researcher to resist perishing. There is no doubt that this rubric is effective in making writing assessment concrete and specific, rather than abstract. Jönsson and Prins (2019) in this regard state that such a feedback criterion serves the function of letting students explicitly link the quality of their work to predefined assessment criteria with a presupposed conviction that these students are in the know of such teacher-designed work quality criteria. They provide clear expectations for the student to gauge their work against and eventually get involved in the development process of criteria-based rubrics. The same argument is presented by both Keengwe and Onchwari (2015) who confirmed that this rubric helps students understand the connection between their work and the supervisor's online feedback.

As to the existence of the construct of feedback system, feed-back, feed-back, feed-up, and feed-forward, through the criteria cited earlier, it is made clearer by the three parts of the second section that the supervisors in question provide ample feed-back, 'how' of the process, about work progress, how to move on, and on how to hone their advancement to develop professional research competencies. As to the feed-up construct which is progressively connected to the previous stage, it deals with the 'where' stage. At this stage it was discovered that the supervisors raise the awareness of the supervisees, through their encouraging comments, to feel self-confident and believe that they have the potential to be good academics. As far as the last part of this section, the "where to next" or feed-forward, the findings showed that according to the respondents, the evaluative comments issued serve as propellers of future incites to do research with the necessary strategies and a critical mind. The gleaned idea is that supervisees obtain timely observations that 
ease them into the rigor of the science of research and understanding of what a quality academic work is and how to go about achieving it and similar works.

Moreover, reflecting on the interconnectedness of these stages reveals that the supervisors were able to smoothly move with students through these stages safely and successfully. Specifically, the feed-back stage was a substantial primary reaction to supervisees' work; the feed-up stage was descriptively scaffolding the supervisee through the process of goal attainment; and the feed-forward stage was the stage where the supervisee started feeling the maturity to become professional academics who are about to fully integrate safely the tormenting seas of academia. A plethora of scholars back up these findings among whom is Zarrinabadi and Rezazadeh (2020) who maintain that the combination of these types into stages reveals to be beneficial for the students/writers in terms of writing motivation and writing anxiety.

In that direction align also the results of Wheatley, McInch, Fleming and Lord's (2015) experimental study. These scholars showed that so as to foster continuous self-directed learning, moving from feeding-back to feeding-forward and going through the stage of feeding-up, students need to be scaffolded through the process of writing, be aware of their weaknesses, and be encouraged so that they could critically reflect upon their products. Always against the same background, Frey and Fisher (2011) opted for a formative assessment system that contains our three famous feedback categories. The idea here is that these steps used ensure understanding of the task including how they will be assessed as part of the feed-back stage. They also ensure feed-up as to what they need to succeed and attain learning goals, and feed-forward as to what they need to effectively learn.

Ultimate evidence comes from Lee (2019) who stressed the salience of students being immersed in the process of feedback by assessing what they teach and teach what they assess, and they connect feed-back to the feed-up stage; and when they give feedback remarks to students for future directions, the feed-back serves the purpose of feedforward, thus bringing the three stages together for the benefit of the students as novice researchers. This is what our findings revealed and as an answer to the first research question, it has been found that our supervisors more or less agree on the same evaluation criteria while evaluating their supervisees' doctoral dissertations. For the second research question, our sample of students attest to the fact that their supervisors vary in the use of the three famous evaluation criteria: In-text feedback marks, In-text feedback comments, End comments, and Rubric development. Additionally, the three previously mentioned criteria target three types of feedback, feed-back, feed-up or feed-forward, with a huge focus of the cyclicity of their utilization.

Finally, the results of the monotonic relationship run to find an association between the types of feedback criteria and types of feedback construct revealed a positive, strong, and statistically significant correlation. This is in line with Dirkx, Brinke, Arts, and Van Diggelen (2019) study results which back up ours and state clearly that the more prevalent the feedback criteria used to assess students' papers, the more predominant and varied is the use of the three kinds of feedback. Therefore, students in our case, or at least with the sample used for this study, seem to be lucky as to the diversification of both criteria and types of feedback; a fact that puts them a strong position to benefit from strategies to get to safe end with their doctorate dissertations/projects and be ready to defend within the norms and regulations of academic viva voices.

\section{References}

Andre, K., \& Heartfield, M. (2011). Nursing and midwifery portfolios: Evidence of continuing competence. Chatswood, NSW: Elsevier Australia.

Arend, B., \& Davis, J. R. (2013). Facilitating seven ways of learning: A resource for more purposeful, effective, and enjoyable college teaching. Stylus Publishing, LLC.

Askew, S. (2000). Feedback for learning. London: Routledge Falmer.

Bajaj, J. K., Kaur, K., Arora, R., \& Singh, S. J. (2018). Introduction of feedback for better learning. Journal of Clinical and Diagnostic Research, 12(12), FC11-FC16. doi:10.7860/jcdr/2018/36744.12402

Bangert-Drowns, R. L., Kulik, C. C., Kulik, J. A., \& Morgan, M. (1991). The instructional effect of feedback in testlike events. Review of Educational Research, 61(2), 213-238. https://doi.org/10.3102/00346543061002213

Bechhofer, F., \& Paterson, L. (2012). Principles of research design in the social sciences. Florence: Taylor and Francis. 
Bitchener, J., \& Knoch, U. (2010). Raising the linguistic accuracy level of advanced L2 writers with written corrective feedback. Journal of Second Language Writing, 19(4), 207-217. https:// doi.org/10.1016/j.jslw.2010.10.002

Bolarinwa, O. (2015). Principles and methods of validity and reliability testing of questionnaires used in social and health science researches. Nigerian Postgraduate Medical Journal, 22(4), 195-201. doi:10.4103/11171936.173959

Breed, R., \& Spittle, M. (2020). Developing game sense in physical education and sport. USA: Human Kinetics Publishers.

Broadbent, J., Panadero, E., \& Boud, D. (2017). Implementing summative assessment with a formative flavour: A case study in a large class. Assessment \& Evaluation in Higher Education, 43(2), 307-322. https://doi.org/10.1080/02602938.2017.1343455

Brookhart, S. M. (2008). How to give effective feedback to your students. Alexandria, VA: Association for Supervision and Curriculum Development.

Burke, D. M., \& Pieterick, J. A. (2010). Giving students effective written feedback. Maidenhead: Open University Press.

Chugh, R., Macht, S., \& Harreveld, B. (2021). Supervisory feedback to postgraduate research students: A literature review. Assessment \& Evaluation in Higher Education, 1-15. https://doi.org/10.1080/02602938.2021.1955241

Dirkx, K., Joosten-ten Brinke, D., Arts, J., \& Van Diggelen, M. (2019). In-text and rubric-referenced feedback: Differences in focus, level, and function. Active Learning in Higher Education, 22(3), 189201. https://doi.org/10.1177/1469787419855208

Dobinson, T., \& Dunworth, K. (2018). Literacy unbound: Multiliterate, multilingual, multimodal. Cham, Switzerland: Springer.

Fazlagić, J. (2017). Images of intellectual capital. Newcastle, UK: Cambridge Scholars Publishing.

Fielder, D. J. (2003). Achievement now! How to assure no child is left behind. Larchmont, NY: Eye on Education.

Frankenberg-Garcia, A. (1999). Providing student writers with pre-text feedback. ELT Journal, 53(2), 100106. https://doi.org/10.1093/elt/53.2.100

Frey, N., \& Fisher, D. (2011). The formative assessment action plan: Practical steps to more successful teaching and learning. Moorabbin, Vic: Hawker Brownlow Education.

Fry, H., Ketteridge, S., \& Marshall, S. (2003). A handbook for teaching and learning in higher education: Enhancing academic practice. Routledge.

Gibbons, J. D., \& Chakraborti, S. (2021). Nonparametric statistical inference. Boca Raton: CRC Press.

Hattie, J. (2009). Visible learning: A synthesis of over 800 meta-analyses relating to achievement. Routledge. https://apprendre.auf.org/wp-content/opera/13-BF-References-et-biblio-RPT2014/Visible\%20Learning_A\%20synthesis\%20or\%20over\%20800\%20Metaanalyses\%20Relating\%20to\%20Achievement_Hattie\%20J\%202009\%20...pdf

Hattie, J., \& Timperley, H. (2007). The power of feedback. Review of Educational Research, 77(1), 81-112. https://doi.org/10.3102/003465430298487

Heritage, M. (2010). Formative assessment: Making it happen in the classroom. Thousand Oaks, California: A SAGE Company.

Holland, M. E. (2008). Feedback research revisited. In D. H. Jonassen (Ed.), Handbook of research on educational communication and technology (pp. 745-783). Mahwah, NJ: Lawrence Erlbaum.

Hyland, K. (2019). Second language writing. New York, NY: Cambridge University Press. 
Hyland, K., \& Hyland, F. (2019). Feedback in second language writing: Contexts and issues. United Kingdom: TJ International Ltd.

Irons, A. (2009). Enhancing learning through formative assessment and feedback. London: Routledge.

Jönsson, A., \& Prins, F. (2019). Transparency in assessment - Exploring the influence of explicit assessment criteria. Frontiers Media SA. doi: 10.3389/feduc.2018.00119

Keengwe, J., \& Onchwari, G. (2015). Handbook of research on active learning and the flipped classroom model in the digital age. Hershey, PA, USA: IGI Global.

Lane, K. L. (2015). Supporting behavior for school success: A step-by-step guide to key strategies. New York: Guilford Press.

Laurillard, D. (2013). Rethinking University teaching: A conversational framework for the effective use of learning technologies. New York, NY: Digital Printing.

Lee, I. (2019). Classroom writing assessment and feedback in 12 school contexts. Singapore Ltd: Springer.

Lipnevich, A. A., \& Smith, J. K. (2018). The Cambridge handbook of instructional feedback. Cambridge: Cambridge University Press.

Mayer, R. E., \& Alexander, P. A. (2017). Handbook of research on learning and instruction. New York: Routledge, Taylor \& Francis Group.

McMillan, J. H. (2013). Sage handbook of research on classroom assessment. Thousand Oaks: SAGE.

McNabb, D. E. (2004). Research methods for political science. New York, NY: M.E. Sharpe Inc.

Mcnabb, D. E. (2015). Research methods in public administration and nonprofit management. New York, NY: Routledge.

McNamara, E. (1999). Positive pupil management and motivation: A secondary teacher's guide. London: David Fulton.

Mory, E. H. (1992). The use of informational feedback in instruction: Implications for future research. Educational Technology Research and Development, 40(3), 5-20. https://doi.org/10.1007/BF02296839

Nelson, K. (2008). Teaching in the digital age: Using the internet to increase student engagement and understanding. Thousand Oaks, CA: Corwin Press.

Nunnally, J. C. (1978). Psychometric theory (2nd Ed.).New York: McGraw-Hill.

OECD. (2001). Evaluation feedback for effective learning and accountability. https://www.oecd.org/dac/evaluation/2667326.pdf

Railean, E. (2019). Handbook of research on ecosystem-based theoretical models of learning and communication. Hershey PA: IGI Global.

Ramírez Balderas, I., \& Guillén Cuamatzi, P. M. (2018). Self and peer correction to improve college students' writing skills. Profile: Issues in Teachers' Professional Development, 20(2), 179194. https://doi.org/10.15446/profile.v20n2.67095

Robins, G. (2012). Praise, motivation, and the child. New York, NY: Routledge.

Rowan, L., \& Bigum, C. (2012). Transformative approaches to new technologies and student diversity in futuresoriented classrooms future proofing education. Dordrecht: Springer Science +Business Media B.V.

Sadler, D. R. (1989). Formative assessment and the design of instructional systems. Instructional Science, 18, 119144. http://dx.doi.org/10.1007/BF00117714

Seidman, I. (2019). Interviewing as qualitative research: A guide for researchers in education and the social sciences. New York, NY: Teachers College Press. 
Spector, J. M., Merrill, M. D., Elen, J., \& Bishop, M. J. (2014). Handbook of research on educational communications and technology. New York, NY: Springer.

Wheatley, L., McInch, A., Fleming, S., \& Lord, R. (2015). Feeding back to feed forward: Formative assessment as a platform for effective learning. Kentucky Journal of Higher Education Policy and Practice, 3(2). https://uknowledge.uky.edu/kjhepp/vol3/iss $2 / 2$

Wiliam

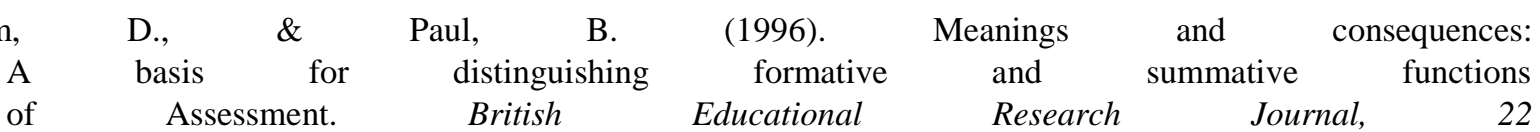

(5), 537-548. https://www.jstor.org/stable/1501668

Zarrinabadi, N., \& Rezazadeh, M. (2020). Why only feedback? Including feed up and feed forward improves nonlinguistic aspects of L2 writing. Language Teaching Research. https://doi.org/10.1177/1362168820960725 